УДК 811.111

DOI: $10.18384 / 2310-712 \mathrm{X}-2016-1-92-98$

\title{
ОСОБЕННОСТИ ДИСКУРСА ВИДЕОИГР
}

\section{Харлашкин М. $\boldsymbol{H}$.}

Московский городской педагогический университет

129226, г. Москва 2-й Сельскохозяйственный проезд, 4, Российская Федерация

Аннотация. В статье рассматриваются различные особенности дискурса видеоигр. Описываются возможности лингвистического анализа данного явления, приводятся определения игры и видеоигры, типы видеоигр, а также элементы и уровни (микро- и макроуровень) анализа дискурса видеоигр. Выделяются и характеризуются различные подходы к анализу языковых единиц дискурса видеоигр. Рассматриваются текстуальные и языковые особенности текстов в видеоиграх и текстов, используемых при их описании и обсуждении (металюдических дискурсов).

Ключевые слова: дискурс, игра, видеоигра, металюдические дискурсы, жанровая экология.

\section{FEATURES OF DISCOURSE OF VIDEOGAMES}

\section{Kharlashkin}

Moscow City Teacher Training University

4, 2nd Selskohozaystveny str., Moscow, 129226, Russian Federation

Abstract. The article focuses on the features of discourse of videogames. The ways to analyze the phenomenon linguistically are described, the definitions of the game and videogame, types of videogames, as well as the elements and levels (micro- and macrolevel) of videogame discourse analysis, are given and analyzed. Different approaches to the analysis of language in videogame discourse are identified. The article also covers the textual and linguistic features of texts in videogames and texts used to describe and discuss them (metaludic discourses).

Key words: discourse, game, videogame, metaludic discourses, genre ecology.

Исследование видеоигр является достаточно новым направлением в современной науке. Его появление традиционно отсчитывается от 2001 г., когда вышел первый номер международного онлайн-журнала Game Studies. Данное событие было охарактеризовано норвежским исследователем Эспеном Арсетом следующим образом: «Вполне возможно, компьютерные игры впервые стали всерьёз рассматриваться учеными как область культуры, значимость которой сложно переоценить» [3] (здесь и далее перевод наш. - М.X.). В настоящее время видеоигры активно исследуются в различных областях науки, таких как информатика, психология, физиология, нарратология, а также сфера образования.

Несмотря на возрастающий интерес к видеоигре как самостоятельному

(c) Харлашкин М. Н., 2016. 
объекту научного исследования, принципы её анализа в рамках лингвистики нельзя считать окончательно оформившимися. По мнению американского исследователя Джеральда Вурхиса, недостаточное внимание к видеоиграм в данной области может быть связано с «анахроничностью письма, старейшей формы передачи информации, и неестественностью его появления в настолько новой информационной среде» $[8$, p. 4]. Одной из первых работ, полностью посвящённых рассмотрению языка в видеоиграх, можно считать опубликованную в 2012 г. монографию британского лингвиста Астрид Энсслин «Язык игр» (The Language of Gaming). В данной работе принимается предложенное Джеспером Джулем определение игры, согласно которому игра представляет собой «систему правил с изменяемым и измеряемым результатом, в которой различным результатам соответствуют различные значения, игрок прилагает усилия для достижения определённого результата, игрок является эмоционально привязанным к результату, а последствия данной деятельности являются договорными» [7, p. 36]. Поскольку данное определение включает в себя как видеоигры, так и более традиционные игровые формы, предлагается дополнительное определение видеоигры как «любой формы программного обеспечения развлекательного характера, содержащей текстовые или графические элементы, предназначенной для любой электронной платформы, такой как персональные компьютеры или игровые приставки, и предполагающей наличие одного или более игроков в физическом или сетевом окружении» [4, p. 31].

Как видно из данного определения, термин «видеоигра» используется как применительно к компьютерным играм, так и к играм, предназначенным для игровых приставок. Несмотря на это, представляется полезным в будущем рассматривать компьютерные игры отдельно, поскольку они, во-первых, являются более распространёнными на современном российском игровом рынке и, во-вторых, характеризуются более высоким соотношением непереводных и переводных продуктов.

Видеоигры в настоящее время представлены большим количеством различных жанров, каждый из которых характеризуется своими особенностями. Представляется возможным выделить группу определённых элементов, присущих всем видеоиграм вне зависимости от конкретного жанра. К таким элементам автор относит игровые правила, задачи различной сложности, механизмы обратной связи и программно-аппаратный интерфейс. Достаточно значимыми при первичном отборе материала для лингвистического анализа видеоигры являются выделенные Джеспером Джулем метатипы игр: эмергентные игры (games of emergence) и прогрессивные игры (games of progression). Эмергентность является «первичной игровой структурой, в которой игра определяется небольшим количеством правил, которые комбинируются и производят большое количество игровых вариаций, для преодоления которых игроки потом конструируют стратегии» [6]. В прогрессивных играх «игроку для достижения результата необходимо совершить определённые действия в заранее заданной последовательности» [6]. Данное разделение является важным при отборе материала, поскольку прогрессивность, предполагающая 
выполнение действий в заданной последовательности, даёт разработчикам большую свободу при проработке игрового мира и, следовательно, составлении внутриигровых текстов. Таким образом, игры, относящиеся к прогрессивному типу, будут, скорее всего, иметь более высокий объём текстового материала, чем игры, относящиеся к эмергентному типу.

Переходя к непосредственному рассмотрению языка в видеоиграх, Э. Арсет предлагает анализировать его в рамках дискурса видеоигр, включающего следующие компоненты:

- язык, используемый игроками в различных информационных средах и на различных коммуникационных платформах для описания игр и игрового процесса;

- язык, используемый профессионалами игровой индустрии, такими как дизайнеры и разработчики, для описания игр и игрового процесса;

- язык, используемый журналистами, политиками, родителями, активистами и другими представителями медиа-индустрии для описания игр и игрового процесса;

- язык, используемый в играх и являющийся частью их пользовательского интерфейса, диалогов, инструкций и повествования;

- язык, используемый в игровых руководствах, аннотациях, рекламе и других «перитекстах» [4, р. 6].

Анализ дискурса видеоигр может осуществляться на двух уровнях: $м$ акроуровне, в рамках которого рассматриваются жанровые особенности текстов, и микроуровне, рассматривающем лексические, грамматические и фонетические особенности отдельных единиц и их сочетаний. Используе- мые при этом методы включают компетентностный подход, исследования дискурса в условиях компьютерной коммуникации (Computer-Mediated Discourse, CMD), конверсационный анализ, корпусный дискурс-анализ, рассмотрение прагматического аспекта дискурса видеоигр и дискурса как инструмента создания социальной идентичности игроков, критический дискурс-анализ, мультимодальный дискурс-анализ (Multimodal Discourse Analysis, MDA) и др. В рамках данных подходов коммуникация в дискурсе видеоигр рассматривается как сложное явление, в определённой степени ограниченное используемой технологической базой, но, с другой стороны, являющееся более социально приемлемым по сравнению с непосредственным общением. С точки зрения критического дискурс-анализа язык понимается в первую очередь как механизм идеологического воздействия, поэтому одной из основных функций дискурса видеоигр Э. Арсет считает «разрушение дискурса власти, налагаемой, например, родителями, учителями и политиками» [4, p. 101].

Основной единицей анализа дискурса видеоигр на макроуровне исследователь называет жанры текста, определяемые как «типы дискурса, используемые в определённых контекстах, <..> имеющие чётко выраженные и узнаваемые нормы организации и структуры, а также определённые коммуникативные функции» [4, p. 5051]. Поскольку в видеоиграх обычно сочетаются несколько жанров текста, предлагается рассматривать их как составляющие жанровой экологии игры, то есть «совокупности часто используемых вместе жанров текста» [4, р. 50]. 
Таким образом, жанровую экологию большинства видеоигр составляют такие специфические жанры текста, как логотипы, титры, игровые правила, описания и диалоги, системные сообщения, меню, и др. Наличие жанровой экологии даёт Э. Арсету основание для рассмотрения таких широко распространённых в дискурсе видеоигр явлений, как интертекстуальность и интермедиальность. Интертекстуальность подразумевает наличие «прямых или косвенных отсылок к другим литературным или нелитературным текстам» [4, р. 53], интермедиальность же понимается как «воссоздание эстетических условностей определённой информационной среды в рамках другой среды, предполагающее перенос присущих ей эстетических и технологических особенностей» $[4$, р. 53]. Ярким примером, иллюстрирующим данные явления, можно считать выпущенную в 2004 г. компьютерную игру The Lord of the Rings: The Battle for Middle Earth, которая, с одной стороны, интертекстуально связана с романом Дж. Толкина «Властелин колец», а с другой - представляет собой интермедиацию одноимённой кинотрилогии П. Джексона. Ещё одним важным понятием, заимствованным из одноимённой работы французского нарратолога Ж. Женетта, является паратекст, определяемый как «то, что позволяет тексту стать книгой и в таком виде предстать перед её читателями и обществом в целом» [5, p. 1]. В рамках дискурса видеоигр паратексты принимают форму «текстов, которые окружают игру и относятся к ней как к первоисточнику» [4, p. 20]. Таким образом, к паратекстам в видеоиграх относятся такие текстовые элементы, как название игры, систем- ные требования, рецензии, сообщения на специализированных игровых форумах, и др.

Микроуровень дискурса видеоигр представлен разнообразными лексическими единицами, используемыми представителями различных игровых сообществ. Примерами таких единиц являются акронимы и инициальные аббревиатуры (Call of Duty - COD, Role-Playing Game - RPG), бленды (kinetic+connect - Kinect), усечённые единицы (modified code - mod), функциональные переносы (boss, tank) и др. Отличительной чертой данных единиц можно считать их краткость, что связано, по всей видимости, с особенностями преобладающей в дискурсе видеоигр синхронной коммуникации: «стремительное развитие мультимедийных технологий в последние два десятилетия обусловило высочайшую скорость прохождения информации, что оказало и продолжает оказывать огромное влияние на особенности восприятия информации пользователем XXI века» [1, с. 33]. Среди текстовых элементов видеоигр можно также выделить прецедентные явления (аллюзии), которые «вмещают в себя знания о многоаспектных явлениях и ситуациях, кодируют информацию о них» [2, с. 71]. Прагматический аспект дискурса видеоигр, рассматриваемый сквозь призму теории речевых актов, позволяет выделить преобладающие типы высказываний: к ним относятся акты побуждения (директивы) и акты, выражающие эмоциональные состояния (экспрессивы). Директивы чаще всего оформляются в виде императивных, модальных, вопросительных и инфинитивных конструкций. Частое использование условных конструкций 
для выражения директивов, по мысли исследователя, «отражает язык программирования, на котором написана игра» [4, р. 92]. Экспрессивы чаще всего имеют форму эксплетивных единиц и единиц, нерасчленённо выражающих эмоциональное состояние говорящего. Директивы и экспрессивы, по мнению автора, выполняют ряд функций: во-первых, они способствуют ознакомлению игрока с правилами игры и вовлекают его в игровой процесс; во-вторых, они предоставляют игроку свободу выбора, и, наконец, в-третьих, они позволяют игроку непосредственно выразить собственное эмоциональное состояние.

Анализируя особенности языка в так называемом «металюдическом» дискурсе (metaludic discourse), то есть дискурсе, представляющем коммуникацию представителей различных игровых сообществ, исследователь выделяет три его особенности, которые также называются им дискурсами: the discourse of 'cool', the discourse of fun и the discourse of appreciation. Первая из указанных особенностей проявляется в частом использовании ненормативной лексики (haha. FIFA, fuck the league [4, p. 110]), инверсии и фрагментированных синтаксических конструкций (You're on it. Sweet. Bursting forward he is. Can't rush [4, p. 110]). К характеристикам второй особенности относится употребление уже упомянутых экспрессивов (Daadadaadadaadaa that was close [4, p. 111]). Наконец, the discourse of appreciation, т.е. оченочный дискурс, характеризуется использованием оценочных наречий (I always wondered why they gave you auto-life?? It was really pointless and downright annoying! [4, c. 112]), элементов самоцензуры (Beowulf on Xbox. That is a horrible piece of ${ }_{* * * *}$ of a game. It did rape my brain with difficulty [4, с. 112]) и использованием заглавных букв (I want to shout it above the roof tops, for everyone to hear, FF7 IS THE GREATEST GAME EVER! AMEN $[4$, c. 112]). Данные особенности ещё раз указывают на одну из основных функций дискурса видеоигр, состоящую в попытке разрушения дискурса господствующей власти.

Видеоигры представляют собой богатый источник материала для лингвистических исследований, при проведении которых необходимо учитывать их специфику как дискурсивных явлений, относящихся к сфере компьютерной коммуникации. Монографию А. Энсслин «Язык игр» как одну из первых работ, затрагивающих эту проблематику, можно считать основополагающим трудом в данной области лингвистики. Анализ дискурса видеоигр в совокупности всех его составляющих может пролить свет на место видеоигр в современной культуре.

\section{ЛИТЕРАТУРА:}

1. Ионина А.А. Особенности создания и восприятия текста в Интернете // Вестник Московского государственного педагогического университета. Серия: Филология. Теория языка. Языковое образование. 2010. № 2 (6) С. 33-39.

2. Чупрына О.Г. Прецедентные явления в британской литературе о подростках (лингвокультурологический подход) // Вестник Московского государственного педагогического университета. Серия: Филология. Теория языка. Языковое образование. 2014. № 3 (15). C. 71-79. 
3. Aarseth E. Computer Game Studies, Year One [Электронный pecypc]. URL: http:// gamestudies.org/0101/editorial.html (дата обращения: 20.08.2015).

4. Ensslin A. The Language of Gaming / A. Ensslin. UK: Palgrave Macmillan, 2012. 224 p.

5. Genette G. Paratexts: Thresholds of Interpretation / G. Genette. Cambridge: Cambridge University Press, 1997. 456 p.

6. Juul J. The Open and the Closed: Games of Emergence and Games of Progression [Электронный ресурc]. URL: http://www.jesperjuul.net/text/openandtheclosed.html (дата обращения: 20.08.2015).

7. Juul J. Half-Real: Videogames Between Real Rules and Fictional Worlds / J. Juul. Cambridge, MA: MIT Press, 2005. 248 p.

8. Voorhees G. Discursive Games and Gamic Discourses [Электронный ресурc]. URL: http:// scholarworks.umass.edu/cgi/viewcontent.cgi?article=1004\&context=cpo (дата обращения: 20.08.2015).

\section{REFERENCES}

1. Ionina A.A. Osobennosti sozdaniya i vospriyatiya teksta $v$ Internete [Specifics of creation and perception of a text in the Internet] // Vestnik Moskovskogo gosudarstvennogo pedagogicheskogo universiteta. Seriya: Filologiya. Teoriya yazyka. Yazykovoe obrazovanie. 2010. no. 2 (6). pp. 33-39.

2. Chupryna O.G. Pretsedentnye yavleniya $\mathrm{v}$ britanskoi literature o podrostkakh (lingvokul'turologicheskii podkhod) [Precedent phenomena in the British literature on adolescents (linguo-cultural approach)] // Vestnik Moskovskogo gosudarstvennogo pedagogicheskogo universiteta. Seriya: Filologiya. Teoriya yazyka. Yazykovoe obrazovanie. 2014. no. 3 (15). pp. 71-79.

3. Aarseth E. Computer Game Studies, Year One [Electronic resource]. URL: http:// gamestudies.org/0101/editorial.html (request date: 20.08.2015).

4. Ensslin A. The Language of Gaming / A. Ensslin. UK: Palgrave Macmillan, 2012. 224 p.

5. Genette G. Paratexts: Thresholds of Interpretation / G. Genette. Cambridge: Cambridge University Press, 1997. $456 \mathrm{p}$.

6. Juul J. The Open and the Closed: Games of Emergence and Games of Progression [Electronic resource]. URL: http://www.jesperjuul.net/text/openandtheclosed.html (request date: 20.08.2015).

7. Juul J. Half-Real: Videogames Between Real Rules and Fictional Worlds / J. Juul. Cambridge, MA: MIT Press, 2005. 248 p.

8. Voorhees G. Discursive Games and Gamic Discourses [Electronic resource]. URL: http://scholarworks.umass.edu/cgi/viewcontent.cgi? article=1004\&context=cpo (request date: 20.08 .2015 ). 


\section{ИНФОРМАЦИЯ ОБ АВТОРЕ}

Харлашкин Михаил Николаевич - аспирант кафедры английской филологии Московского городского педагогического университета;

e-mail: therover@rambler.ru

\section{INFORMATION ABOUT THE AUTHOR}

Kharlashkin Mikhail - postgraduate student of English Philology department of Moscow City Teacher Training University;

e-mail: therover@rambler.ru

\section{БИБЛИОГРАФИЧЕСКАЯ ССЫЛКА}

Харлашкин М. Н. Особенности дискурса видеоигр // Вестник Московского государственного областного университета. Серия: Лингвистика. 2016. № 1. С. 92-98. DOI: $10.18384 / 2310-712 \mathrm{X}-2016-1-92-98$

\section{BIBLIOGRAPHIC REFERENCE}

M. Kharlashkin. Features of discourse of videogames // Bulletin of Moscow State Regional University. Series: Linguistics. 2016. no 1. pp. 92-98. DOI: 10.18384/2310-712X-2016-1-92-98 